\title{
Las trampas del «yo» o sobre una «guerra sin memoria ni memoriales»
}

\author{
Gerardo de la Fuente Lora \\ Facultad de Filosofía y Letras \\ Benemérita Universidad Autónoma de Puebla \\ Leticia Flores Farfán \\ Facultad de Humanidades \\ Universidad Autónoma del Estado de Morelos
}

Nada es trágico para el animal, que no cae en la trampa del yo. Bataille, La experiencia interior

Tal parece que la humanidad, a pesar de todas las catástrofes y violencias que ha padecido, se resiste a ser borrada de la faz del planeta. Katrina no desapareció del todo a Nueva Orleáns; el terremoto de 1985 no desdibujó por completo la cartografía de la Ciudad de México; la bomba de Hiroshima no aniquiló a todos los potenciales enemigos a quienes estaba dirigida. Y si la destrucción no ha sido absoluta no es porque la fuerza devastadora de estas experiencias no fuera descomunal, sino porque ninguna violencia ha sido, hasta ahora, capaz de erradicar la posibilidad de nuevos mapas, de inéditas cartografías estéticas y políticas para todo aquello que permanece con vida bajo los escombros.

Si continuamos estando aquí, si volvemos una y otra vez a construir/reconstruir es porque, y esta nos parece que es acaso la enseñanza fundamental de Nietzsche, nunca acabamos del todo de olvidar. Y ese no olvido, esa ineludible memoria, como afirman 
Sennet y Foucault ${ }^{1}$ leyendo a San Agustín, es el castigo al que la humanidad toda fue condenada como deudora solidaria del acto de rebeldía que Adán y Eva realizaron contra Dios. La memoria de esa primera y primaria insubordinación quedó materialmente grabada en los juegos de superficie de nuestros cuerpos, lapidariamente inscrita en cada uno de los movimientos autónomos e incontrolados de un cuerpo humano que desde la evicción del Paraíso comparece rebelde y desafiante como la primera pareja lo fue con Dios. El castigo eterno decretado para los primeros transgresores por su desafío y la deuda impagable a la que la humanidad fue condenada por ese acto de desobediencia cometido por los padres originarios fue la caída en el tiempo, en la finitud, en la enfermedad y, por si esto no fuera ya bastante, se acompañó de una historia de culpa y «concientización», de una abrumadora huella mnémica de la sentencia condenatoria del acto de rebelión inaugural que marca la frontera del sentido y su narración. Lo que se graba en la memoria se graba a fuego nos dice Nietzsche porque «(...) sólo lo que no cesa de doler permanece en la memoria $»^{2}$.

Pero, ¿porqué seguir pensándonos a partir de esa condena? ¿No había muerto ya Dios? Es más, ¿no lo habíamos matado? Tal pareciera que no tenemos seguridad de que el golpe fatal propinado hubiese sido lo suficientemente certero como para afirmar sin dubitación que Dios no está agónico sino irremisiblemente muerto. Muestra de esta incertidumbre compareció cuando la modernidad, el capitalismo, el sujeto, se enfilaron recta y rápidamente a su disolución, cuando arrasaron con todo lo que podía arrasarse, pero hubo algo que de pronto los detuvo y jaló, una supervivencia inesperada de sí mismos que los hizo regresar para borrarla. Pero no pudieron, porque lo que queda al final no es algo, sino una huella, una ausencia, una marca material, una archiescritura derrideana, un signo hendido en el hueso de lo que es. En el vocabulario nietzscheano, se trata del tema no de la Muerte de Dios, sino de la per-

${ }^{1}$ Cf. Richard SENNET y Michel FOUCAULT, «Sexualidad y soledad», en: El Viejo Topo 61 (1981), 47-54 pp.

2 Friedrich NIETZSCHE, Genealogía de la moral, trad. Andrés Sánchez Pascual, Madrid: Alianza Editorial 1979, II, 3. 
vivencia de su sombra. Y así, nos dice el autor de La Gaya Ciencia: «Nuevas luchas. - Después de que Buda hubiera muerto, su sombra siguió mostrándose aún durante siglos en una caverna - una sombra monstruosa y terrible. Dios ha muerto: pero tal vez, dada la naturaleza de la especie humana, sigan existiendo durante milenios cavernas en las que se muestre su sombra. Y nosotros - ¡nosotros también tenemos aún que vencer su sombra!» ${ }^{3}$.

Un resabio, una reliquia, la perseverancia de algo tan fantasmal como una resolana, es eso lo que no deja irse del todo al Buda. Tienen razón Gilles Deleuze y Félix Guattari cuando sostienen que el tema de la Muerte de Dios no era demasiado relevante, en sí mismo, para Nietzsche. Según ellos el autor de Más Allá del Bien y del Mal explica que ese fallecimiento «no interesa más que al último papa»: «Nietzsche dice - según se afirma en El Anti Edipo- que lo importante no es la noticia de que Dios está muerto, sino el tiempo que tarda en dar sus frutos» ${ }^{4}$. El lapso en espera de la resolución, el tiempo de la huella, del espectro, que fue hasta hace poco el nuestro y que quizá lo siga siendo, es el dominio en que tuvo validez la filosofía entera de Jacques Derrida.

La deconstrucción, pensamiento de la diferencia y la diferición, de la re-iterabilidad, comprende bien el mensaje nietzscheano en el sentido de que son los signos casi inmateriales, las marcas que recuerdan una incisión, una circuncisión, las que hacen del devenir un retornar. Todo vuelve no porque Dios exista o no, sino porque en las tablas de Moisés permanece una exacción, un escarbamiento, un bajo relieve, un grabado que no se puede borrar, que nos obliga a leer eternamente, no dable al olvido porque en sentido estricto no es, es una ausencia, una escritura braile, como todas, para el tacto del ciego.

3 Friedrich NIETZSCHE, La Ciencia Jovial, trad. Germán Cano, Madrid: Biblioteca Nueva $2001, \S 108$.

${ }^{4}$ Gilles DELEUZE y Félix GUATTARI, El Anti Edipo. Capitalismo y Esquizofrenia, Barcelona: Paidós 1985, p. 112. 
La escritura, materialidad de una incisión, de una sustracción, es de suyo, paradójicamente, una borradura. Es por ello que no puede fundar en sí y por sí una reiteración, una replicación. En Roma del año 539 a.e., según nos dice Eulalio Ferrer ${ }^{5}$, comenzaron a garabatearse en los muros y en las columnas de las plazas públicas no sólo edictos, avisos personales o mensajes políticos, sino diversos anuncios públicos relativos a fallecimientos y, con ello, se ampliaba la difusión de la noticia de la muerte de alguien encargada con anterioridad exclusivamente a los pregoneros. Sin embargo, los muros se blanqueaban constantemente con una lechada de agua y cal para borrar los avisos anteriores y dar cabida a nuevos muertos; lo escrito queda borrado, condenado al olvido, para dar paso a una inscripción, a una nueva memoria, una nueva escritura permanentemente sitiada, como telón de fondo, por aquello que ha sido borrado. Escritura y muerte, olvido y memoria comparecen de manera paradójica y tensa siempre que emerge un acontecimiento en donde se dan cita inscripción y borradura. Así también nos lo hace ver Nicole Loraux en un importante estudio sobre las políticas del olvido en Atenas Clásica ${ }^{6}$, en donde analiza tanto la censura de la tragedia La toma de Mileto (y la multa que le fue impuesta al poeta trágico Frínico por haber montado la representación), como el «decreto de amnistía» que la democracia restaurada hizo promulgar en el 403 para todos los que habían participado en la rebelión oligarca del 405. Loraux afirma que la rebelión oligarca dejó a Atenas enfrascada en una lucha civil, cruenta y desagarradora, de la que sólo podrían salir si los atenienses juraban respetar un decreto de amnistía en el que fueran perdonados todos aquellos que habían participado en el levantamiento en donde fueron asesinados miles de demócratas. Olvidar, borrar el asesinato cometido era condición necesaria para lograr que Atenas viviera en paz y se encaminara a

5 Cf. Eulalio FERRER, El lenguaje de la inmortalidad. Pompas fúnebres, México: FCE 2003, p. 159.

${ }^{6}$ Cf. Nicole LORAUX, «De la amnistía y su contrario», en: YERUSHALMI; LORAUX; MOMMSEN; MILNER; VATTIMO, Usos del olvido. Comunicaciones al Coloquio de Royaumont, Buenos Aires: Nueva Visión 1998. 
recuperar la prosperidad perdida. La borradura y/o amnistía del 403, continúa la historiadora, estructuró una política del perdón en donde se borró lo acontecido y no se permitió que en la memoria colectiva quedaran grabados ni el conflicto, ni el asesinato, ni el resentimiento entre atenienses. «Borrar - afirma Loraux - es destruir por sobrecarga: sobre la tablilla oficial blanqueada a la cal se vuelve a pasar otra capa de cal y, una vez tapadas las líneas condenadas a desaparecer, ahí está listo el espacio para un nuevo texto (...)». El decreto de amnistía ha sido valorado como una escritura orientada a la defensa simbólica y material de la memoria colectiva y la identidad cívica; sin embargo, la conformación de la nueva memoria se instaura sobre un olvido que, como afirma Loraux siguiendo a Freud, no debe ser entendido como una ausencia plena, sino como esa «superficie oscurecida que cobija lo que sólo estaba reprimido». Ciudad sobre ciudad, memoria sobre memoria ${ }^{7}$. Para que el devenir sea un volver, un iterar, además de la marca, hace falta que a la hendidura se agregue una acción, un ritual, una política. La compulsión a la repetición proviene entonces de una nemotecnia, de unas políticas de la memoria, de una gestión de las marcas en los cuerpos y en los textos. Citando a Nietzsche, Deleuze y Guattari presentan así la memoria humana como política de la crueldad. Comentan Deleuze y Guattari:

Nietzsche dice: se trata de dar al hombre una memoria; y el hombre, que se ha constituido por una facultad activa de olvido, por una represión de la memoria biológica, debe hacerse otra memoria, que sea colectiva, una memoria de las palabras y no de las cosas, una memo-

7 De aquí el extraordinario carácter de la política del olvido examinada por George Orwell en su 1984. Ahí, Winston, el protagonista, describe la borradura de la historia practicada por el Ingsoc, como una eliminación completa sin residuo alguno, como una «vaporización»: «La gente se esfumaba sencillamente durante la noche. El nombre del sujeto apresado ya no estaría en los registros, borrada en todas partes cualquier alusión a su historia y su paso por la vida, anulado, tachado para siempre tal como si jamás hubiera existido. Había una palabra que mencionaba este hecho. Vaporizado», en: George ORWELL, 1984, México: Grupo Editorial Tomo 2002, p. 25. Una devastación sin huellas, incluso sin monumentos para disimular las cuchilladas, las desgarraduras, tal es la utopía desaforada examinada por el autoritarismo desplegado por el Ministerio de la Verdad en la narración orwelliana. 
ria de los signos y no de los efectos. Sistema de la crueldad, terrible alfabeto, esta organización que traza signos en el mismo cuerpo: «Tal vez no haya nada más terrible y más inquietante en la prehistoria del hombre que su nemotecnia... Esta nunca ocurriría sin suplicios, sin mártires y sacrificios sangrientos cuando el hombre juzgaba necesario crearse una memoria; los más temibles holocaustos y los compromisos más horribles, las mutilaciones más repugnantes, los rituales más crueles de todos los cultos religiosos.... ${ }^{8}$.

Crear una nemotecnia es llenar el hueco de la escritura. Colmar el bajo relieve, suprimir el surco. Es decir, no dibujar sino pintar; no grabar sino ilustrar. Es elevar monumentos. Hacer de la marca en el cuerpo no una incisión sino un abultamiento. No sólo amputar sino tumorizar; o bien amputar primero haciendo raja en la carne al tiempo que se suple la desgarradura por alguna forma de metástasis. «La humanidad - afirma Foucault ${ }^{9}$ - no progresa lentamente, de combate en combate, hasta una reciprocidad universal en la que las reglas sustituirán para siempre a la guerra; instala cada una de estas violencias en un sistema de reglas y va así de dominación en dominación»; la regla, sigue diciendo Foucault en complicidad con Nietzsche, «(...) es el placer calculado del encarnizamiento, es la sangre prometida» porque no hay nada grande en el mundo que no haya nacido regado de sangre ${ }^{10}$.

¿Existe una relación directa e ineludible entre escritura y política de la crueldad? Tal vez. Por lo menos hasta ahora parece haber sido así. Es sabido que la invención de la escritura alfabética abrió camino al nacimiento del pensamiento crítico toda vez que la posibilidad de preservar el saber hizo factible tener una relación no sacralizada con él como la que se mantenía en las sociedades tipificadas como de oralidad primaria, según la clasificación de Walter Ong ${ }^{11}$. Cuestionar el relato de los orígenes no significaría

8 DELEUZE y GUATTARI, El Anti Edipo, 150-151 pp. Citan en el texto a NIETZSCHE, Genealogía de..., II, 2-7.

9 Michel FOUCAULT, «Nietzsche, la genealogía y la historia», en: Microfísica del poder, Madrid: Ediciones de La Piqueta 1980, p. 17.

10 Cf. NIETZSCHE, Genealogía de..., II, 6.

11 Cf. Walter ONG, «La escritura reestructura la conciencia», en: Oralidad y escritura. 
ya perder la comunidad, desvanecer la tradición. Pero si es cierto que escribir es en un sentido borrar, la escritura de la crítica tuvo que traer consigo, para perseverar, una nueva crueldad, un nuevo monumento. La iterabilidad del signo no está disociada de la institución del tormento. Enunciar, dijo en algún momento Deleuze, consiste siempre en juzgar. Escribir, en todo caso, significa siempre anatemizar lo que se nombra. O bien, siguiendo a Tzvetan Todorov, podemos decir que memoria no es el antónimo perfecto del olvido porque todo acto de memoria implica una selección en donde se excluyen, se borran, se olvidan al mismo tiempo que se conservan y se resguardan rasgos específicos de los acontecimientos vividos ${ }^{12}$. Lo que perturba e indigna de los verdugos hitlerianos o stalinistas, advierte Todorov, no es que conserven el pasado mejor que otros individuos o grupos diferentes a ellos - pues éstos también seleccionan y conservan en un afán de constituir su propia memoria-, sino que se «apropien el derecho de controlar la elección de los elementos que conservan» ${ }^{13}$.

Tecnologías de la palabra, México: FCE 1987, 81-116 pp.

12 T. TODOROV, «Los abusos de la memoria», en: Memoria y ciudad, Medellín: Corporación Región 1997. Versión PDF consultada en www.region.org.co

13 Tal y como señala Derrida en su libro Mal de archivo, el concepto de archivo abriga en sí la memoria del nombre arkhé, es decir, de lo originario, lo primero, el comienzo pero, a un mismo tiempo, del mandato. Se coordinan así dos principios: el físico, histórico u ontológico que se refiere al allí donde las cosas comienzan y el principio según la ley, «allí donde los hombres y los dioses mandan, allí donde se ejerce la autoridad, el orden social, en ese lugar desde el cual el orden es dado - principio nomológico». «(...) el sentido de "archivo", su solo sentido, [afirma Derrida] le viene del arkheîon griego: en primer lugar, una casa, un domicilio, una dirección, la residencia de los magistrados superiores, los arcontes, los que mandaban. A los ciudadanos que ostentaban y significaban de este modo el poder político se les reconocía el derecho de hacer o de representar la ley. Habida cuenta de su autoridad públicamente así reconocida, es en su casa entonces, en ese lugar que es su casa (casa privada, casa familiar o casa oficial), donde se depositan los documentos oficiales. Los arcontes son ante todo sus guardianes. No sólo aseguran la seguridad física del depósito y del soporte sino que también se les concede el derecho y la competencia hermenéuticos. Tienen el poder de interpretar los archivos. Confiados en depósito a tales arcontes, estos documentos dicen en efecto la ley: recuerdan la ley y llaman a cumplir la ley. Para estar así guardada, a la jurisdicción de este decir la ley le hacía falta a la vez un guardián y una localización. Ni siquiera en su custodia o en su tradición hermenéutica podían prescindir los archivos de soporte ni residencia», en: Jacques DERRIDA, Mal de archivo: www.jacquesderrida.com.ar [Derrida en castellano]. 


\section{III}

Pero ¿por qué obcecarse en la crueldad? Para no morir. El monumento que se empeña en borrar el carácter evanescente de la huella, quisiera que la memoria fuese perenne. Como nos lo hace saber Eulalio Ferrer ${ }^{14}$, en el Poema de Gilgamesh, narración de la civilización asirio-babilonia que mereció ser cincelada en piedra después del Enuma Elish, se realiza una profunda meditación sobre la muerte tras el fallecimiento de Enkidu, amigo entrañable de Gilgamesh. El dolor irrespirable que le provoca a Gilgamesh la pérdida de Enkidu hace que organice una celebración póstuma en la que no sólo se llorará la partida de su entrañable compañero, sino que se le erigirá una suntuosa estatua de oro, plata, cobre y lapislázuli que le asegurará la inmortalidad. La rememoración escultural-escritural otorga a los difuntos la vida eterna en la memoria y en el corazón de los hombres vivos. En Grecia antigua los honores fúnebres alrededor de la sepultura y los epitafios permitían que el cadáver del difunto siguiera encarnando los valores de vida, juventud y belleza de los que gozaba el héroe antes de morir. Dejar insepulto un cadáver, no marcar la localización de su entierro, sería condenarlo a la muerte más terrible, a la del ultraje del cuerpo por las aves de rapiña y los perros salvajes, al olvido eterno. Por ello, la política de la crueldad y la memoria, construye siempre monumentos funerarios. De ahí, como relata Todorov, la importancia que adquirió el trabajo de recuperación creado por Serge Klarsfeld en Francia para conformar un memorial de los deportados judíos. Este Memorial - en donde se restablecen los nombres, las fechas de nacimiento y las de partida hacia los campos de exterminio de los judíos deportados - se erige como un monumento de dignificación humana y un testimonio indiscutible de resistencia contra la aniquilación, la borradura sin rastro que pretendieron los nazis con la aniquilación total, con la llamada «solución final» que Himmler caracterizó «como una página gloriosa de nuestra historia que no ha sido jamás escrita y no lo será jamás». Esta historia no escrita pero grabada en los cien- 
tos de miles de cadáveres, en el dolor de los sobrevivientes, en el espacio vacío de los campos se enfrentará a otra memoria, a aquella que será escrita para resistir el olvido absoluto, la muerte implacable que implica el no recuerdo. Usos del olvido y de la memoria.

Múltiples rituales mortuorios de occidente inician con la inscripción del nombre del difunto en la sepultura. En la introducción a una antología de epigramas funerarios griegos María Luisa del Barrio Vega comenta que: «A través de su nombre en la estela el difunto conserva un vínculo con la vida, con lo que pervive en el recuerdo de los vivos gracias al sepulcro y al nombre grabado en él. A esta finalidad conmemorativa responden los términos griegos para designar el monumento sepulcral: mnêma "recuerdo", sêma "señal", etc. El elemento central de un epitafio es, por tanto, el nombre del difunto» ${ }^{15}$.

Es a través del nombre del difunto grabado en las lápidas mortuorias o repetido como un rumor incesante en la palabra de los vivos como se logra vencer la finitud de la existencia y se hace pervivir la identidad del portador más allá de la muerte. El nombre nos permite saber quién es el que yace en esa sepultura y cuál es la fama que lo libera de la mortaja mortuoria. Sin sepultura el cadáver se pierde en el anonimato del olvido, se exilia a un mismo tiempo del universo de los vivos y de los muertos porque no deja rastro ni seña de su paso por esta vida. El cuerpo insepulto está condenado a una inhumanidad radical porque deviene despojo que será devorado y del que no quedará ningún rastro de su humanidad.

El nombre emerge como la marca que determina la identidad del difunto. Nada es que no haya sido nombrado, es decir, fijado por la identidad que su apelativo le otorga. El hombre es finito y ello quiere decir, en principio, que no hace huella. Para que la marca no se borre hace falta la Historia ${ }^{16}$, la recapitulación de los nom-

15 María Luisa DEL BARRIO VEGA, «Introducción», en: Epigramas funerarios griegos, trad. María Luisa del Barrio Vega, Madrid: Gredos 1992, p. 17.

16 Afirma Roberto Pittaluga que: «Una política de archivo es, en todo momento, una política sobre lo que se recuerda y lo que se olvida, una política de memoria, una dimensión de la escritura de la historia. La práctica historiográfica se inicia, como decía Michael de Certeau, con el gesto de poner aparte, y, por ese procedimiento, convertir en "documentos" algunos objetos repartidos de otro modo (...) La primera acción historiadora funda el ma- 
bres de todos los muertos. «La palabra del hombre - dice Octavio $\mathrm{Paz}$ - es hija de la muerte. Hablamos porque somos mortales: las palabras no son signos, son años». Los combates por la historia son las disputas por los cadáveres o, más bien, por el resguardo de sus cementerios que no son más que archivos de identidad en donde se clasifica, cataloga y ordena a los muertos como estrategia discursiva para fijar el recuerdo. Lo extraordinario - o quizá, lo terriblees que esta estrategia de memoria funda la comunidad. ¿Acaso no hay manera de escapar a la memoria cruel? Como epígrafe a uno de sus textos más sorprendentes, Jean Baudrillard cita una elucubración extraordinaria de Elías Caneti.

Una ocurrencia dolorosa: la de que a partir de un punto preciso en el tiempo, la historia dejó de ser real. Sin percatarse de ello, la totalidad del género humano de repente se habría salido de la realidad. Todo lo que habría sucedido desde entonces ya no sería en absoluto verdad, pero no podríamos darnos cuenta de ello. Nuestra tarea y nuestro deber consistirían ahora en descubrir este punto, y hasta que diéramos con él, no nos quedaría más remedio que perseverar en la destrucción actual ${ }^{17}$.

\footnotetext{
terial que será objeto de su indagación, distinguiendo de la masa de las prácticas sociales y culturales aquello que la misma acción de distinción configurará como dato. Se trata, entonces, de que la conversión de un objeto en documento tenga lugar, es decir, que se intervenga en el espacio social otorgando un lugar al objeto que se transforma en documento. Localizar un objeto como documento es posible si se cuenta con un lugar - físico y social- que instituye la conversión. Éste es un lugar que permite y que prohíbe, cuya doble función, dice de Certeau, "vuelve posibles algunas investigaciones, gracias a coyunturas y problemáticas comunes", pero al mismo tiempo "vuelve imposibles" otras. Es la relación entre lo posible y lo no-posible, la combinación entre permiso y prohibición sobre la que se sostiene el discurso histórico, siempre situado», en: Roberto PITTALUGA, «Democratización del archivo y escritura de la historia», en: Memoria abierta, 4-5 pp. Documento en formato PDF en: www. memoriaabierta.org.ar/encuentro_archivos/programa.php

17 Cf. Jean BAUDRILLARD, «Patafisica del año 200», en: La Ilusión del Fin. La huelga de los Acontecimientos, trad. Thomas Kauf, Barcelona: Anagrama 1993, p. 9.
} 
Ya alguno de los estudios freudianos habían apostado por mostrar el carácter ficcional de la huella, es decir, de la inscripción de la Ley. La compulsión a la repetición era inevitable porque el momento de la incisión no había acontecido. Como afirma Catherine Millot, «(...) el mito del asesinato del padre original tiene por función, más que colmar un vacío, marcar sencillamente el lugar de un agujero» ${ }^{18}$. Nadie puede ubicar históricamente el origen, nadie puede relatar este «acontecimiento puro» en donde nada acontece: «El relato de lo prohibido es un relato prohibido», como sostiene Derrida ${ }^{19}$, porque la huella, la Ley, es límite siempre infranqueable, pues comparecemos y nos sujetamos ante y por ella pero sin penetrarla ni afrontarla.

La Ley, sin embargo, no es sólo enunciado normativo, precepto general, sino también reglamento, instructivo, manual de procedimiento, guía de trámites con original, dos copias y la hoja rosa. Dos de los ejemplos más impactantes de la comprensión de la modernidad como dinámica no sólo legal sino recursiva, retardataria, torpe, farragosa, áspera, son Freud y Kafka. Frente al cartesianismo que nos ofreció la certeza de ser cada uno de nosotros un «adentro», un espacio interior indubitable, el autor de la Interpretación de los Sueños nos mostró que tal forma de la subjetividad se ejerce al costo de la compulsión a la repetición. Yo pienso y no sólo existo, sino que insisto, vuelvo una y otra vez a una escena originaria inacabable porque perdida, siendo a la vez soberano libre y racional de mí mismo y burócrata de la gestión de mi experiencia. En el mismo tiempo que el psicoanalista, viendo ahora por la ventana hacia la ciudad y el estado, Franz Kafka miró al mundo como un perseverar de los insectos, individuos mediados, cada uno, por la inmensidad de la gerencia del vivir, de los trámites y probanzas que hay que recorrer una y otra vez, en posposición infinita del proceso de nunca acabar. Althusser habló en su momento de la constitución de la subjetividad individual como de una batalla perdida:

18 Catherine MILLOT, Freud, anti-pedagogo, trad. Irene Agoff, Barcelona: Paidós 1982, p. 101.

19 Jacques DERRIDA, «Ante la Ley», en: La filosofía como institución, Barcelona: Juan Granica 1984, p. 114. 
(...) la única guerra sin memorias ni memoriales, una guerra que la humanidad finge no haber librado jamás, aquella que cree siempre haber ganado de antemano simplemente porque la ha sobrevivido, vivido y engendrado como cultura en la cultura humana, guerra que cada instante se declara a todos y cada uno de sus vástagos que han proyectado, torneado y rechazado para sí mismos, en la soledad y contra la muerte, la decisión de recorrer la larga marcha forzada que convierte en criaturas humanas, sujetos, a iniciales larvas mamíferas ${ }^{20}$.

Pero perdemos; siempre queda un residuo, la amiba en nosotros persevera. Al mecanismo de sujetamiento, a su legalidad la corroe una ausencia, una escena original pospuesta siempre y un último trámite a culminar para completar la gestión de nosotros mismos. Es la Ley. Está prohibido morir y está prohibido ser inmortales. Con dos copias, por duplicado. La animalidad y la inmortalidad acechan. La huella en tanto inscripción reclama un acopio, una memoria, una estrategia de sentido para que lo reprimido no irrumpa con una violencia directamente proporcional a la fuerza impuesta para su represión.

¿Qué ocurriría si ahora nos planteáramos la posibilidad de salirnos de una subjetividad interior entrampada en el teatro de la crueldad y el jueguecito de la parentela? ¿Qué pasaría, si aceptáramos por fin que no somos cada uno más que una pluralidad de simulacros, encantadores artificios en representaciones sin fin de múltiples papeles? Tal vez podríamos comprender con mayor fuerza esa concepción del «ser como mirar» que se remonta a la antigüedad griega y de la que da cuenta Jean Pierre Vernant cuando afirma:

En primer lugar, ver y saber son la misma cosa; si ideîn «ver» y eidénai «saber» son dos formas de un mismo verbo, si eîdos «apariencia», «aspecto visible» significa también «carácter propio», «forma inteligible»,

${ }^{20}$ Louis ALTHUSSER, «Freud y Lacan», en: Posiciones, México: Grijalbo 1977, p. 33. 
es porque el conocimiento se interpreta y expresa a través del mundo de la visión. Conocer es, pues, una forma de ver. En segundo lugar, ver y vivir son también la misma cosa. Para estar vivo hace falta ver la luz del sol y a la vez ser visible a los ojos de todos. Morir significa perder la vista y la visibilidad al mismo tiempo, abandonar la claridad del día para penetrar en otro mundo, el de la Noche donde, perdido en la Tiniebla, uno queda despojado a la vez de su propia imagen y de su mirada ${ }^{21}$.

Hacernos cómplices de esta idea es abrirnos a una nueva legalidad de la subjetividad con la cual no llenamos el hueco ni accedemos, por fin, a esa escena original siempre ausente en tanto que nunca acontecida, sino que entramamos nuestra identidad en un juego de apariciones en donde no somos seres ni exteriores ni interiores, sino más bien espectros, fantasmas por fin alcanzados, sueños realizados.

La pregunta por nuestro ser, la inquietante interrogación de ¿quién soy? no encontrará, quizá, otra respuesta que la dada por Bataille en Sobre Nietzsche cuando afirma: «(...) ¡esta mujer que abrazo está moribunda y la pérdida infinita de los seres, que fluyen incesantemente, deslizándose fuera de sí mismos, SOY YO!» ${ }^{22}$. O tal vez una nueva subjetividad espectral consista en alcanzar el ser de los jardines que nos propone Henry Miller:

Ya no miro a los ojos de la mujer que estrecho en mis brazos, los atravieso a nado, mi cabeza, brazos y piernas también, y observo que detrás de las órbitas de esos ojos se extiende un mundo inexplorado, un mundo de cosas futuras, un mundo carente de lógica (...) El ojo, liberado del yo, ya no revela ni elimina nada, se desplaza a lo largo de la línea del horizonte, viajero ignorante y eterno (...) He quebrado el muro que crea el nacimiento y el trazado de mi viaje es curvo y cerrado, sin ruptura (...) Mi cuerpo entero debe devenir un rayo perpetuo de luz cada vez más intenso (...) Aprieto mis oídos, mis ojos y mis labios. Antes de que vuelva a ser hombre, probablemente existiré como parque ${ }^{23}$.

${ }^{21}$ Jean Pierre VERNANT, «El hombre griego», en: A.A.V.V., El hombre griego, Madrid: Alianza Editorial 1995, 22-23 pp.

22 Georges BATAILLE, Sobre Nietzsche. Voluntad de suerte, trad. Fernando Savater, Madrid: Taurus 1979, p. 171.

23 Henry MILLER, Trópico de Capricornio, México: Alfaguara 1978, 150-151 pp. Deleuze 


\section{RESUMEN}

¿Qué ocurriría si nos planteáramos la posibilidad de salirnos de una subjetividad interior entrampada en el teatro de la crueldad? ¿Qué pasaría si aceptáramos por fin que no somos cada uno más que una pluralidad de simulacros, encantadores artificios en representaciones sin fin de múltiples papeles? Tal vez podríamos comprender con mayor fuerza esa concepción del «ser como mirar» que se remonta a la antigüedad griega. Hacernos cómplices de esta idea es abrirnos a una nueva legalidad de la subjetividad con la cual no llenamos el hueco ni accedemos, por fin, a esa escena original siempre ausente en tanto que nunca acontecida, sino que entramamos nuestra identidad en un juego de apariciones en donde no somos seres ni exteriores ni interiores, sino más bien espectros, fantasmas por fin alcanzados, sueños realizados.

Palabras clave: memoria; escritura; política de la crueldad; identidad personal; Nietzsche.

\section{ABSTRACT}

What if we raise the possibility of leaving subjectivity as trapped in the interior of a theater of cruelty? What if we finally accept that we are not each rather than a plurality of drills, charming artifices in order to represent multiple roles? Maybe we could understand this concept more strongly of «being like watching» that dates back to ancient Greece. Make us accomplices to this idea is open ourselves to a new legality of subjectivity with which do not fill the gap or access at last to the original scene always absent in while never happened, but we enter our identity in a game of appearances where we are not exterior or interior beings, but spectra, ghosts finally achieved, dreams come true.

Keywords: memory, writing, politics of cruelty; personal identity; Nietzsche.

\footnotetext{
y Parnet citan y comentan este texto de Miller en: Gilles DELEUZE y Claire PARNET, Diálogos, Valencia: Pre-textos 1980, p. 55.
} 